\title{
Investigação das propriedades do concreto convencional com adição de resíduos de
}

\section{pneu e metacaulim}

\author{
Investigation of the properties of conventional concrete with addition of waste tire and metakaolin \\ Investigación de las propiedades del hormigón convencional con adición de llanta de desecho y \\ metaolina
}

Recebido: 30/03/2021 | Revisado: 10/04/2021 | Aceito: 13/04/2021 | Publicado: 26/04/2021

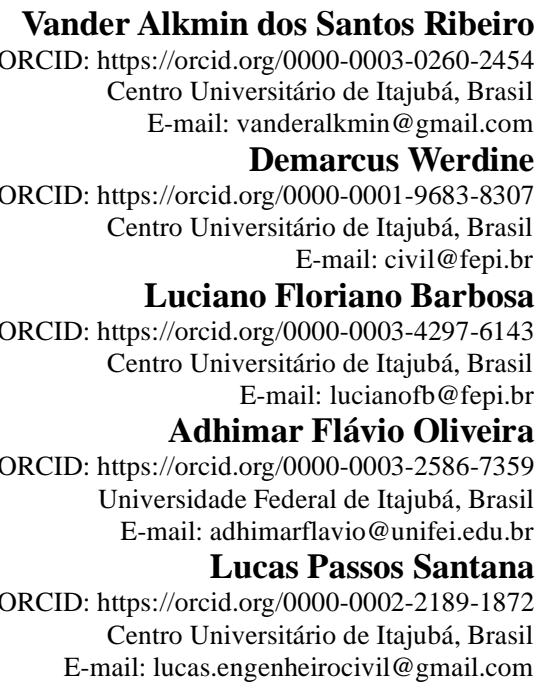

\begin{abstract}
Resumo
O pneu, por ser essencial para as atividades da vida moderna, se tornou um dos produtos de maior consumo no mundo e um dos resíduos mais problemáticos por sua difícil decomposição na natureza. Devido a isso, uma solução para o problema é o aproveitamento de resíduos de pneus na substituição à areia na composição do concreto podendo ser uma alternativa para o desenvolvimento sustentável do setor da construção civil. Através do método $\mathrm{ABCP} / \mathrm{ACI}$, os corpos de prova foram moldados com traço de 1,29:2,28:0,5 e seus resultados mostraram que a resistência à compressão diminuiu com o aumento da porcentagem de resíduos de pneu. Contudo, os corpos de prova adicionado com $15 \%$ de metacaulim apresentaram um aumento da resistência a compressão com o crescimento da porcentagem de resíduo de pneu. Também observou que os valores de absorção de água diminuíram da amostra REF-15M para a amostra com 15\%RP-15M. Além disso, observou-se também um aumento da absorção de água nas amostras ausentes de metacaulim para as amostras com adição de $15 \mathrm{M}$ de metacaulim.
\end{abstract}

Palavras-chave: Concreto; Resíduo de pneu; Resistência a compressão; Módulo de elasticidade.

\begin{abstract}
The tire, being essential for the activities of modern life, has become one of the most consumed products in the world and one of the most problematic residues due to its difficult decomposition in nature. Due to this, a solution to the problem is the use of tire waste to replace sand in the composition of concrete, which can be an alternative for the sustainable development of the civil construction sector. Through the ABCP/ ACI method, the specimens were molded with a trace of 1.29: 2.28: 0.5 and their results showed that the compressive strength decreased with increasing percentage of tire waste. However, the specimens added with $15 \%$ metakaolin showed an increase in compressive strength with the increase in the percentage of tire residue. He also observed that the water absorption values decreased from the REF-15M sample to the sample with 15\% RP-15M. In addition, there was also an increase in water absorption in the absence of metakaolin samples for samples with the addition of $15 \mathrm{M}$ metakaolin.
\end{abstract}

Keywords: Concrete; Waste tire; Compressive strength; Modulus of elasticity.

\section{Resumen}

El neumático, fundamental para las actividades de la vida moderna, se ha convertido en uno de los productos más consumidos del mundo y uno de los residuos más problemáticos por su difícil descomposición en la naturaleza. Por ello, una solución al problema es el uso de llantas de desecho para reemplazar la arena en la composición del hormigón, lo que puede ser una alternativa para el desarrollo sostenible del sector de la construcción civil. Mediante el 
método $\mathrm{ABCP} / \mathrm{ACI}$, las probetas se moldearon con una línea 1.29: 2.28: 0.5 y sus resultados mostraron que la resistencia a la compresión disminuyó con el aumento del porcentaje de residuos de llantas. Sin embargo, las muestras agregadas con $15 \%$ de metacaolín mostraron un aumento en la resistencia a la compresión con el aumento en el porcentaje de residuos de neumáticos. También señaló que los valores de absorción de agua disminuyeron de la muestra REF-15M a la muestra del 15\% RP-15M. Además, también hubo un aumento en la absorción de agua en ausencia de muestras de metacaolín para muestras con la adición de metacaolín 15M.

Palabras clave: Hormigón; Desechos de llantas; Resistencia a la compresión; Módulo de elasticidad.

\section{Introduçãa}

O pneu, por ser essencial para as atividades da vida moderna, se tornou um dos produtos de maior consumo no mundo e um dos resíduos mais problemáticos por sua difícil decomposição na natureza. Quando se tornam inservíveis, os pneus são colocados em aterros onde podem permanecer por mais de 500 anos. Isto constitui um problema ambiental que pode ser solucionado pela engenharia. Neste contexto, a reciclagem surge como instrumento promotor do bem-estar ecológico e social (Silva et al., 2019).

Um dos desafios para o problema é o aproveitamento de resíduo de pneu na substituição da areia na composição do concreto, sendo uma das alternativas para o desenvolvimento sustentável e para a melhoria das propriedades do concreto. A reutilização do pneu como agregado do concreto pode assumir um papel importante na preservação do meio ambiente, pois, além de diminuir a extração de recursos naturais, como a areia e a brita, também controla o acúmulo desses resíduos nas áreas urbanas (Romualdo et al., 2011).

Segundo Benson (1995), a utilização dos pneus triturados em vez dos materiais de construção utilizados convencionalmente, apresenta diversos benefícios: densidade reduzida, melhor propriedades de drenagem e, melhor isolação térmica e acústica. Entretanto, à substituição de resíduos de pneu pela areia no concreto reduz da resistência à compressão do concreto.

Granzotto \& Souza (2013) constataram que após a incorporação de resíduo de pneu ao concreto nas proporções de $5 \%, 10 \%$ e 15\%, a resistência à compressão diminuiu de 45,8 MPa para 12,6 MPa.

Para melhorar o desempenho das propriedades do concreto, a utilização de adições minerais pozolânica, como o Metacaulim, tem sido uma grande escolha, compensando algumas limitações impostas pela aplicação do agregado leve, como o aumento da resistência à compressão (Rossignolo \& Oliveira, 2007). Essa adição mineral proporciona reatividade com o hidróxido de cálcio presente na pasta de cimento, efeito esse denominado de reação pozolânica (Silva et al., 2020).

A reação pozolânica reduz a porosidade e o teor de hidróxido de cálcio na matriz de cimento, assim como melhora a qualidade da zona de transição agregado-matriz, promovendo a melhoria das propriedades do concreto como à resistência mecânica e à durabilidade (Rossignolo \& Oliveira, 2007).

Singh e Patel (2017) avaliaram a resistência a compressão do concreto com resíduo de pneu na concentração de 0 a $20 \%$ e a utilização do metacaulim como substituto parcial do cimento na proporção de $15 \%$.

Seus resultados revelaram que a resistência a compressão do concreto diminuiu com a adição de resíduo de pneu na proporção de 0 a $20 \%$ e com a utilização de metacaulim houve um aumento da resistência a compressão devido à reação pozolânica com $15 \%$.

Barbuta (2017) investigou a resistência a compressão do concreto com resíduos de pneu na proporção de 25\%, 30\%, $40 \%$ e $50 \%$. Seus resultados indicaram que os valores da resistência a compressão do concreto diminuíram com a adição do resíduo de pneu.

Rameswari et al. (2017) analisaram a resistência a compressão do concreto nas idades de 7 e 28 dias. Seus resultados apontaram que a resistência à compressão do concreto diminuiu de $68,3 \%$ para 6,5\% com a adição de resíduo de pneu nas proporções de $5 \%$ a $25 \%$. 
Modoi e Sârbu (2017) averiguaram a resistência a compressão do concreto com resíduos de pneu na proporção de $10 \%, 20 \%$ e $30 \%$ nas idades de 7 e 28 dias. Os resultados da resistência à compressão do concreto confirmaram que houve uma diminuição gradual com a adição de resíduo de pneu.

\section{Metodologia}

O método utilizado para pesquisa é a Experimental, pois envolve qualquer tipo de experimento que auxilie no desenvolvimento da pesquisa. E o estudo se configura numa abordagem quantitativa, pois após a aplicação da pesquisa e de posse dos dados coletados, chega-se à última etapa do trabalho, que é a apresentação dos resultados obtidos. Eles são compostos por números, dados, quadros e gráficos, que vão mostrar os resultados de forma quantitativa (Estrela, 2018). Esta pesquisa foi desenvolvida no laboratório de Materiais de construção civil do Centro Universitário de Itajubá- FEPI com auxílio do Professor Luciano Floriano Barbosa.

Para a moldagem dos corpos de prova foi utilizado o agregado miúdo proveniente da areia natural classificada como areia fina e para o agregado graúdo utilizou-se a brita 1 com dimensão máxima característica de $19 \mathrm{~mm}$, por ser uma granulometria utilizada nos canteiros de obras da região. A granulometria dos agregados seguiu os procedimentos descritos na (NBR NM 248, 2003). Para o resíduo de borracha, devido não existir uma norma específica, utilizou-se (ASTM C 792, 2020), com algumas adaptações. Inicialmente, pesou-se duas amostras de $500 \mathrm{Kg}$, cada uma, que foram colocadas em estufa por um período de 4 horas, a uma temperatura de $110^{\circ} \mathrm{C}$.

Depois desse intervalo, as amostras foram resfriadas ao ar durante 2 horas e então inseridas em uma proveta contendo $\left(500 \mathrm{dm}^{3}\right)$ de querosene à temperatura de $25{ }^{\circ} \mathrm{C}$. Após a inserção do resíduo, foi feita a agitação do frasco para eliminação das bolhas de ar e então realizou-se a leitura do nível atingido pelo líquido no gargalo do frasco indicando o volume $\mathrm{em}^{3}$ ocupado pelo conjunto (água-agregado). Com esses dados determinou-se a massa específica da borracha.

Utilizou-se o procedimento de ensaio estabelecido pela (NBR NM 52, 2009) para determinação da massa específica do agregado miúdo e (NBR NM 53, 2009) para a determinação da massa específica do agregado graúdo.

O cimento empregado foi o CP-II-E-32 e a sua caracterização foi realizada de acordo com os procedimentos descritos nas seguintes normas: (NBR NM 248, 2003) e (NBR 16605, 2017).

O aditivo plastificante utilizado foi o Cemix 2000, com alto poder de redução de água. Tem ação simultânea de plastificante e superplastificante, dependendo da dosagem utilizada, e não altera significativamente o tempo de pega. Como plastificante foi realizado primeiramente uma pré-mistura do cimento e dos agregados, adicionando cerca de 70\% do volume de água. Em seguida, foi adicionado Cemix 2000 ao concreto, obedecendo à dosagem necessária, e complementar com o restante da água. Também permite concretos com ótima trabalhabilidade e baixa relação água-cimento, o que proporciona um concreto de grande durabilidade, baixa permeabilidade e de altas resistência.

O metacaulim utilizado foi o Metacaulim HP Ultra. As propriedades físicas e químicas do produto estão especificadas nos Quadros 1 e 2. 
Quadro 1. Especificações do metacaulim utilizado nesta pesquisa.

\begin{tabular}{|c|c|c|}
\hline Elemento & Tipico & Limite (NBR 15.894) \\
\hline $\mathrm{SiO}_{2}$ & $55,5 \%$ & $44,0 \%$ a $65,0 \%$ \\
\hline $\mathrm{Al}_{2} \mathrm{O}_{3}$ & $36,5 \%$ & $32,0 \%$ a $46,0 \%$ \\
\hline $\mathrm{Fe}_{2} \mathrm{O}_{3}$ & $2,0 \%$ & - \\
\hline $\mathrm{TiO}_{2}$ & $1,0 \%$ & - \\
\hline $\mathrm{CaO}$ & $0,5 \%$ & $\mathrm{CaO}+\mathrm{MgO}<1,5 \%$ \\
\hline $\mathrm{MgO}$ & $0,5 \%$ & $\mathrm{CaO}+\mathrm{MgO}<1,5 \%$ \\
\hline $\mathrm{K}_{2} \mathrm{O}$ & $1,5 \%$ & $0,658 \mathrm{~K}_{2} \mathrm{O}+\mathrm{Na}_{2} \mathrm{O}<1,5 \%$ \\
\hline $\mathrm{Na}=$ & $0,1 \%$ & $<0,5 \%$ \\
\hline $\mathrm{SO}_{3}$ & $0,1 \%$ & $<1,0 \%$ \\
\hline Perda ao fogo & $2,0 \%$ & $<4,0 \%$ \\
\hline
\end{tabular}

Fonte: Metacaulim HP Ultra.

Quadro 2. Propriedades físicas do metacaulim utilizado nesta pesquisa.

\begin{tabular}{|c|c|c|}
\hline Propriedades & Tipico & Limite (NBR 15.894) \\
\hline Finura $(<\# 325-44 \mu \mathrm{m})$ & $5,0 \%$ & $<10,0 \%$ \\
\hline Área especifica $\left(\mathrm{cm}^{2} / \mathrm{g}\right)$ & 230000 & $>150000$ \\
\hline Massa especifica $\left(\mathrm{kg} / \mathrm{dm}^{3}\right)$ & 2,55 & - \\
\hline Massa unitária & 0,60 & \\
\hline
\end{tabular}

Fonte: Metacaulim HP Ultra.

O método da ABCP (Associação Brasileira de Cimento Portland) foi utilizado para determinar a dosagem do concreto. Após a caracterização dos agregados e do resíduo, primeiramente estipulou-se a resistência característica do concreto em Fck= $25 \mathrm{MPa}$, e utilizou-se o desvio padrão de 4,0, obtendo-se assim, uma resistência de dosagem Fcj =32 MPa.

Utilizando-se a curva de Abrams, estabeleceu-se a relação água/cimento em 0,50; chegando assim ao consumo de materiais necessários para a produção de $1 \mathrm{~m}^{3}$ de concreto (sem adição de borracha) sendo que a apresentação do traço ficou da seguinte forma: $1 ; 1,29 ; 2,28 ; 0,50$. Sendo respectivamente as proporções de cimento; areia; brita e fator água/cimento.

O Quadro 3 mostra a composição do concreto. Quatro traços foram moldados, sendo um de referência (sem adição de resíduo), outros três com adição de (5\% a 15\% em resíduo de pneu, em relação ao agregado miúdo). Também foram moldados, sendo uma referência (sem adição de resíduo e $15 \%$ de metacaulim), outros três com adição de (5\% a 15\% em resíduo de pneu e $15 \%$ de metacaulim). 
Quadro 3. Composição do concreto.

\begin{tabular}{|c|l|c|l|}
\hline AMOSTRA & \multicolumn{1}{|c|}{ Composição } & AMOSTRA & \multicolumn{1}{c|}{ Composição } \\
\hline REF & $\begin{array}{l}\text { 0\% de residuo e } 0 \% \\
\text { de metacaulim }\end{array}$ & REF-15M & $\begin{array}{l}\text { 0\% de residuo e 15\% } \\
\text { de metacaulim }\end{array}$ \\
\hline $5 R P$ & $\begin{array}{l}5 \% \text { de residuo e 0\% } \\
\text { de metacaulim }\end{array}$ & 5RP-15M & $\begin{array}{l}5 \% \text { de residuo e 15\% } \\
\text { de metacaulim }\end{array}$ \\
\hline $10 R P$ & $\begin{array}{l}10 \% \text { de residuo e } 0 \% \\
\text { de metacaulim }\end{array}$ & 10RP-15M & $\begin{array}{l}10 \% \text { de residuo e } \\
15 \% \text { de metacaulim }\end{array}$ \\
\hline 15RP & $\begin{array}{l}15 \% \text { de residuo e 0\% } \\
\text { de metacaulim }\end{array}$ & 15RP-15M & $\begin{array}{l}15 \% \text { de residuo e } \\
15 \% \text { de metacaulim }\end{array}$ \\
\hline
\end{tabular}

Fonte: Autores (2021).

Na produção do concreto foi utilizada uma betoneira de eixo inclinado com capacidade de 55 litros e a colocação dos materiais na betoneira seguiu a seguinte ordem: agregado graúdo, água, cimento, areia e resíduo de pneu.

De acordo com a norma (NBR 5738, 2015), os corpos de prova foram moldados em moldes cilíndricos de diâmetro igual a $15 \mathrm{~cm}$ e altura de $30 \mathrm{~cm}$. Após vinte e quatro horas foram desenformados e armazenados em câmara úmida para processo de cura por 28 dias. Em seguida, os corpos de prova cilíndricos, foram capeados na base e no topo com mistura de enxofre.

Após a execução de cada mistura de concreto realizou-se o ensaio para a determinação da consistência do concreto pelo abatimento do tronco de cone (Slump test), conforme (NBR NM 67, 1998). Os valores da tolerância foram identificados segundo a (NBR 7212, 2012).

Para o ensaio de resistência a compressão foram moldados 5 corpos de prova para o traço, utilizando os procedimentos da (NBR 5739, 2018), que prescreve uma metodologia, na qual devem ser ensaiados à compressão os corpos de prova cilíndricos de concreto, moldados conforme a (NBR 5738, 2016).

A determinação da absorção de água por imersão, índice de vazios e massa específica dos concretos foram realizados segundo os procedimentos descritos na (NBR 9778, 2009).

Quatro corpos de prova foram reservados e cortados ao meio em marmoraria, respeitando o limite mínimo de 2500 $\mathrm{cm}^{3}$ para concretos preparados com agregados de dimensão máxima de até $50 \mathrm{~mm}$, conforme a (NBR 9778, 2009). Estes corpos de prova foram moldados sem o uso de óleo mineral, geralmente utilizado como revestimento nos moldes.

Aos 28 dias, as 4 amostras foram secas em estufa à temperatura de $105^{\circ} \mathrm{C}$ por $72 \mathrm{~h}$. Após esse período, as amostras foram pesadas e os valores registrados foram denominados de massa seca.

As amostras foram imersas em água por 72 horas à temperatura de $23^{\circ} \mathrm{C}$. Foram mantidas com $1 / 3$ de seu volume pelo período de $4 \mathrm{~h}, 2 / 3$ de seu volume por mais $4 \mathrm{~h}$ e completamente imersas nas $64 \mathrm{~h}$ restantes.

Após esse período, as amostras foram enxugadas com pano absorvente, pesadas e os valores registrados foram denominados de massa saturada. Imediatamente após, as amostras foram submetidas à pesagem em balança hidrostática e os valores registrados foram denominados de massa imersa em água.

Para o ensaio do modulo de elasticidade foram moldados 5 corpos de prova para o traço, utilizando os procedimentos (NBR 6118, 2014) e (NBR 8522, 2017).

Segundo a (NBR 8522, 2017), o módulo de deformação estático para um material sob compressão axial simples é determinado a partir da declividade da curva tensão-deformação em corpos de prova cilíndricos sob carregamento uniaxial. O corpo de prova é submetido a cargas crescentes e a cada incremento de carga mede-se a deformação correspondente. 


\section{Resultados e Discussão}

O Quadro 4 mostra os valores da composição granulométrica do agregado miúdo e do resíduo de pneu. Para o diâmetro máximo (DM), o valor encontrado para a areia e o resíduo de pneu é de 2,36 mm e 4,75 mm, sendo classificados como agregado miúdo, pois seu diâmetro está situado entre $0,075 \mathrm{~mm}$ e 4,8 mm.

Os valores do módulo de finura (MF), para os agregados foram de 1,82 e 3,85; respectivamente para a areia e resíduo de pneu. O valor encontrado para os resíduos de pneu está bem próximo aos resultados encontrados na literatura, que podem variar em média de 3,27 a 3,85, podendo chegar a 5,63 (Fioriti e Akasaki 2007). Os resultados demonstram que há uma maior quantidade, em porcentagem, ou seja, de massa retida de grãos de resíduo de pneu na peneira com abertura de 1,18 mm, enquanto a maior quantidade de massa retida do agregado miúdo foi de $0,30 \mathrm{~mm}$.

Observando a granulometria da amostra de areia em relação ao resíduo de pneu, pode-se observar que o resíduo de pneu apresenta uma distribuição granulométrica não similar ao da areia.

Quadro 4. Granulometria da areia e resíduo de pneu.

\begin{tabular}{|c|c|c|c|c|c|c|c|}
\hline \multicolumn{2}{|c|}{ Peneiras (ABNT) } & \multicolumn{3}{|c|}{ Areia } & \multicolumn{3}{|c|}{ Residuo de pneu } \\
\hline $\begin{array}{c}\text { Abertura } \\
\text { (mm) }\end{array}$ & $\begin{array}{l}\text { Peneira } \\
\text { (número) }\end{array}$ & $\begin{array}{c}\% \\
\text { Retida }\end{array}$ & $\begin{array}{l}\text { \% Retida e } \\
\text { Acumulada }\end{array}$ & $\begin{array}{c}\% \\
\text { passa }\end{array}$ & $\begin{array}{c}\% \\
\text { Retida }\end{array}$ & $\begin{array}{l}\text { \% Retida } \\
\text { Acumulada }\end{array}$ & $\begin{array}{c}\% \\
\text { passa }\end{array}$ \\
\hline 4,75 & 4 & 1,00 & 1,00 & 99,00 & 4,00 & 4,00 & 96,00 \\
\hline 2,36 & 8 & 1,00 & 2,00 & 98,00 & 19,00 & 23,00 & 77,00 \\
\hline 1,18 & 16 & 5,00 & 6,00 & 94,00 & 41,00 & 64,00 & 36,00 \\
\hline 0,60 & 30 & 16,00 & 23,00 & 77,00 & 31,00 & 95,00 & 5,00 \\
\hline 0,30 & 50 & 35,00 & 58,00 & 42,00 & 4,00 & 99,00 & 1,00 \\
\hline 0,15 & 100 & 34,00 & 92,00 & 8,00 & 1,00 & 100,00 & 0,00 \\
\hline \multicolumn{2}{|c|}{ Fundo $(g)$} & 8,00 & 100,00 & 0,00 & 0,00 & 100,00 & 0,00 \\
\hline \multicolumn{2}{|c|}{ Massa Total $(\mathrm{g})$} & \multicolumn{2}{|c|}{299,56} & \multicolumn{4}{|c|}{300,64} \\
\hline \multicolumn{2}{|c|}{$\begin{array}{l}\text { Diåmetro máximo } \\
(\mathrm{mm})\end{array}$} & \multicolumn{2}{|r|}{2,36} & \multicolumn{4}{|c|}{4,75} \\
\hline \multicolumn{2}{|c|}{ Módulo de Finura } & \multicolumn{2}{|r|}{1,82} & \multicolumn{4}{|c|}{3,85} \\
\hline \multicolumn{2}{|c|}{$\begin{array}{ll}\text { Massa } & \text { especific } \\
\left(\mathrm{g} / \mathrm{cm}^{3}\right) & \end{array}$} & \multicolumn{2}{|r|}{2,32} & \multicolumn{4}{|c|}{1,09} \\
\hline
\end{tabular}

Fonte: Autores (2021).

O Quadro 5 mostra os valores da composição granulométrica da Brita 1. Na Quadro 5 observou-se que o diâmetro das partículas está incluído na faixa de brita 1 com diâmetro máximo de 19,00 mm, pois está relacionado a grandeza associada à distribuição granulométrica do agregado, correspondente à abertura de malha quadrada, em mm, à qual corresponde uma porcentagem retida acumulada igual ou imediatamente inferior a $5 \%$.

Os resultados demonstram que há uma maior quantidade, em porcentagem, ou seja, de massa retida de grãos de resíduo de pneu na peneira com abertura de $12,50 \mathrm{~mm}$. 
Quadro 5. Granulometria da Brita.

\begin{tabular}{|c|c|c|c|}
\hline \multicolumn{3}{|c|}{ Peneiras (ABNT) } & Brita \\
\hline Abertura (mm) & $\%$ Retida & $\begin{array}{c}\text { \% Retida e } \\
\text { Acumulada }\end{array}$ & $\%$ passa \\
\hline 31,50 & 0,00 & 0,00 & 100,00 \\
\hline 25,00 & 0,00 & 0,00 & 100,00 \\
\hline 19,00 & 0,00 & 0,00 & 100,00 \\
\hline 12,50 & 53,00 & 53,00 & 47,00 \\
\hline 9,50 & 38,00 & 91,00 & 9,00 \\
\hline 6,30 & 9,00 & 100,00 & 0,00 \\
\hline Fundo (g) & 0,00 & 100,00 & \\
\hline Massa Total (g) & 5,00 & & \\
\hline $\begin{array}{l}\text { Diåmetro máximo } \\
\text { (mm) }\end{array}$ & 19,00 & \\
\hline Módulo de Finura & 3,85 & \\
\hline $\begin{array}{l}\text { Massa especifica } \\
\text { (g/cm }{ }^{3} \text { ) }\end{array}$ & 2,90 & \\
\hline
\end{tabular}

Fonte: Autores (2021).

A Figura 1 mostra as curvas granulométricas da areia e do resíduo de pneu. As curvas da distribuição granulométrica mostram que a areia é pertencente a faixa da zona utilizável inferior, pois o módulo de finura está na faixa de valores entre 1,55 e 2,20 e o resíduo de pneu está fora da faixa da zona utilizável superior.

Comparando os valores da areia com o resíduo de pneu observa-se que não satisfaz a condição de substituição parcial dela quanto ao critério do diâmetro dos grãos. Segundo a NBR 7211 (2009), versão corrigida 2019, através da faixa de valores do agregado miúdo, observou-se que o valor do modulo de finura da areia é classificada como areia fina $(1,72<\mathrm{MF}<2,11)$ e o resíduo de pneu é classificado como areia muito grossa $(\mathrm{MF}>2,71)$.

Figura 1. Curvas granulométricas-agregados miúdos.

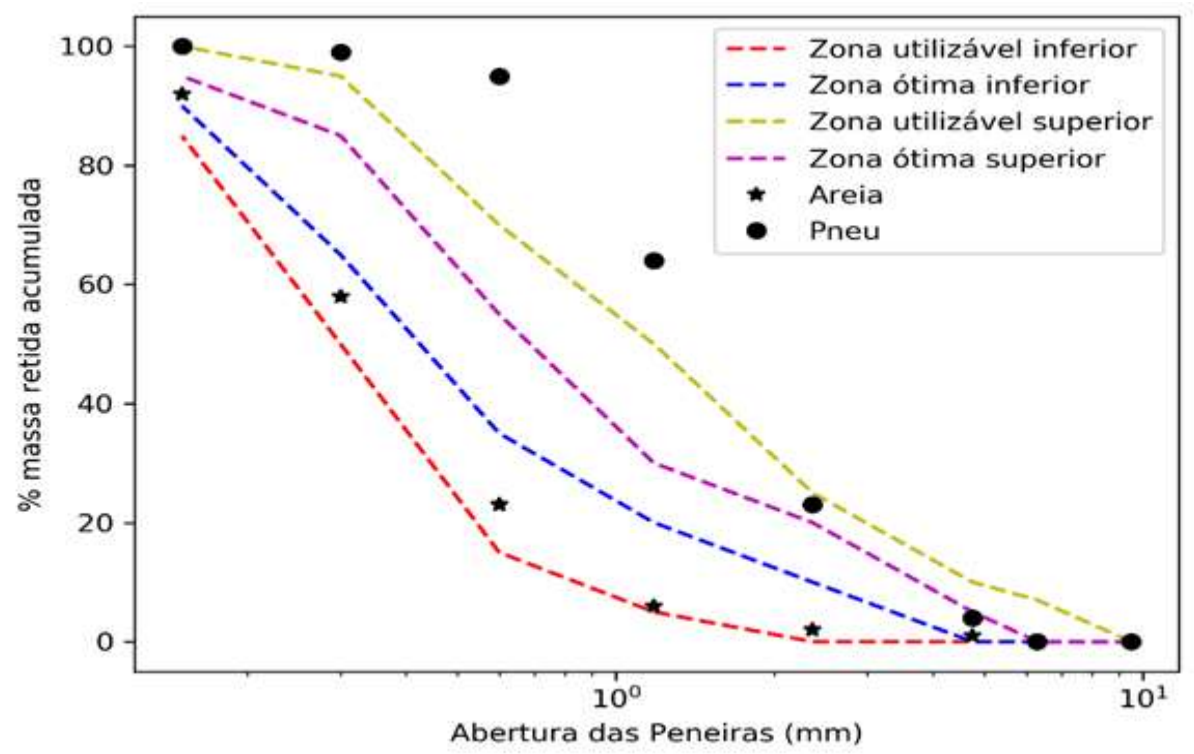

Fonte: Autores (2021).

A Figura 2 mostra os resultados encontrados nos ensaios de consistência do concreto (Slump Test) para o concreto fresco com porcentagens de substituição parcial do volume do agregado miúdo por resíduos de pneu de 5\%, 10\% e 15\% e a 
adição de $15 \%$ de metacaulim.

Através dos resultados apresentados observou-se que não houve alteração nos valores da trabalhabilidade do concreto REF para o concreto com 5RP. Entretanto, observou-se um aumento da trabalhabilidade de (100 \pm 20$) \mathrm{mm}$ do concreto com 15RP.

Através dos resultados apresentados observou-se que o concreto com 10RP-15M para o concreto com 15RP-15M houve um aumento de $(100 \pm 20) \mathrm{mm}$ para $(120 \pm 20) \mathrm{mm}$ nos valores da trabalhabilidade com a adição de $15 \%$ de metacaulim.

A incorporação de resíduos de pneu nos compósitos de matriz cimentícia pode alterar seu comportamento quanto à fluidez e, consequentemente, diminuir a trabalhabilidade do concreto. A diminuição da trabalhabilidade ocorre devido à área superficial apresentada pela borracha $\left(0,03 \mathrm{~m}^{2} / \mathrm{g}\right)$ é maior em relação à areia $(0,01 \mathrm{~m} / \mathrm{g})$ substituída.

Este comportamento é explicado pela menor massa específica da borracha, o que implica em colocar um volume maior de material seco, portanto, uma área superficial maior para agregado de borracha em comparação com areia, aumentando assim a área a ser molhada (Moreira et al, 2014). Assim, necessita-se aumentar a relação água/cimento (a/c) para manter a trabalhabilidade.

Portanto, à medida que se adiciona o resíduo de pneu, a trabalhabilidade do concreto diminui necessitando de mais água de amassamento para tornar a mistura trabalhável, o que contribui para uma menor resistência (Moreira et al, 2014).

Figura 2. Slump Test do concreto.

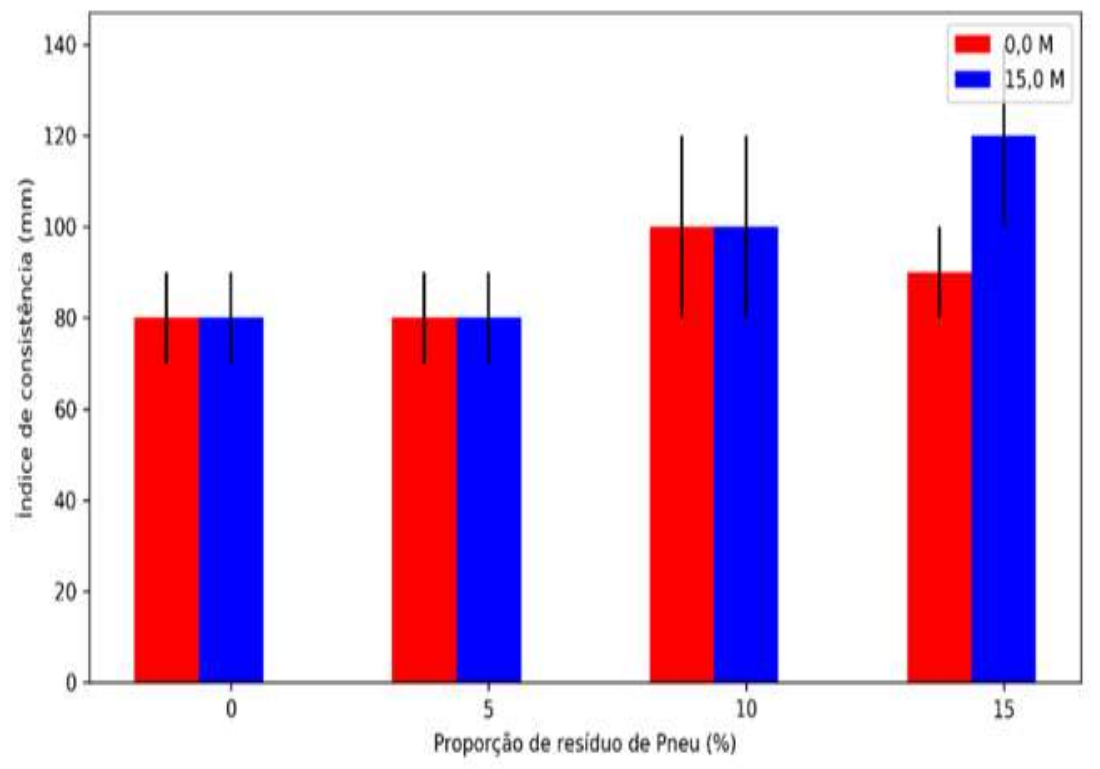

Fonte: Autores (2021).

Nacif et al. (2012) “concluíram que o desempenho de compósitos do concreto com adição de borracha é afetado não só pela quantidade de resíduos de pneu, mas também pelo tamanho das partículas. A borracha com pequena granulometria resulta em menor densidade e porosidade aparente e maior resistência à compressão".

Segundo Wanke et al. (2011), outro fator que influencia a trabalhabilidade do concreto é a característica hidrofóbica do resíduo de pneu (estrutura química apolar das partículas) que repele a água.

A Figura 3 mostra os valores encontrados para a resistência à compressão axial aos 28 dias para o concreto. Através dos resultados, observou-se que a resistência a compressão diminuiu de $(34,79 \pm 0,34)$ MPa da amostra REF para 
$(25,65 \pm 0,16) \mathrm{MPa}$ da amostra com 15RP.

A redução da resistência a compressão verificada com a incorporação do resíduo de pneu é atribuída a uma maior incorporação de ar aprisionado quando da produção de concreto com resíduo e à má aderência entre o concreto e o resíduo de pneu (Granzotto, 2013).

Os resíduos de pneu funcionam como vazios no interior do concreto e quanto maior o teor de ar aprisionado, maior a porosidade e consequentemente menor a sua resistência (Freitas et al., 2009).

Também observou que a resistência à compressão do concreto aumentou de $(18,35 \pm 0,09) \mathrm{MPa}$ na amostra REF.$15 \mathrm{M}$ para $(23,79 \pm 0,45)$ da amostra $15 \mathrm{RP}-15 \mathrm{M}$. Isto ocorre devido ao fato que quando se adiciona metacaulim ocorre uma densificação na zona de transição interfacial (ITZ) entre o concreto e as partículas do pneu, assim como também aumenta a densidade do concreto, que por sua vez melhora significativamente a sua resistência à compressão (Selung et al., 2013; Congkou et al., 2011). A Figura 4 também mostra que com a adição de metacaulim a porcentagem de $15 \%$ houve uma diminuição nos valores da resistência a compressão do concreto.

Isso ocorreu devido ao uso de maior quantidade de aditivo para atingir uma boa trabalhabilidade e também por o metacaulim não conseguir suprir as propriedades que o cimento traz ao concreto, obtendo então menores tensões de resistência à compressão para o concreto com porcentagens de substituição do cimento por metacaulim de 15\% (Souza et al., 2016).

Figura 3. Resistência à compressão axial do concreto (Fck) a 28 dias.

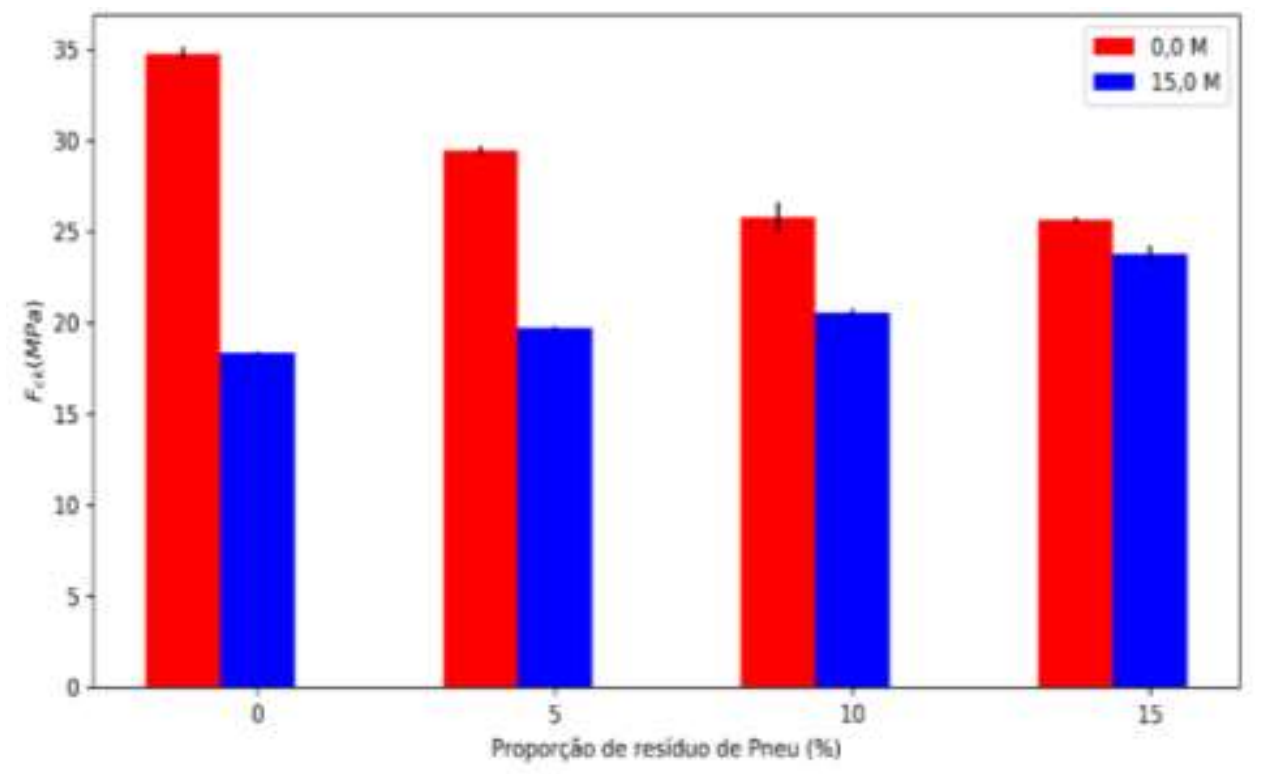

Fonte: Autores (2021).

A Figura 4 mostra os valores encontrados para o módulo de elasticidade a 28 dias para o concreto. A Figura 4 mostra que o valor do módulo de elasticidade diminuiu de $(34,79 \pm 0,40)$ GPa da amostra REF. para $(25,65 \pm 0,15)$ GPa da amostra com 15RP. O fator que explica a redução do valor do módulo de elasticidade no concreto com resíduos de pneu pode ser atribuído não só a elasticidade da borracha, mas também à redução de sua resistência a compressão pois, segundo Neville (1995), o módulo de elasticidade e a resistência à compressão são duas propriedades diretamente ligadas entre si.

Os estudos de Fioriti (2007) comprovam esta relação, pois relatam que assim com a resistência do concreto foi reduzida com adição de resíduo de pneu o módulo de elasticidade também diminui. 
Figura 4. Módulo de elasticidade do concreto a 28 dias.

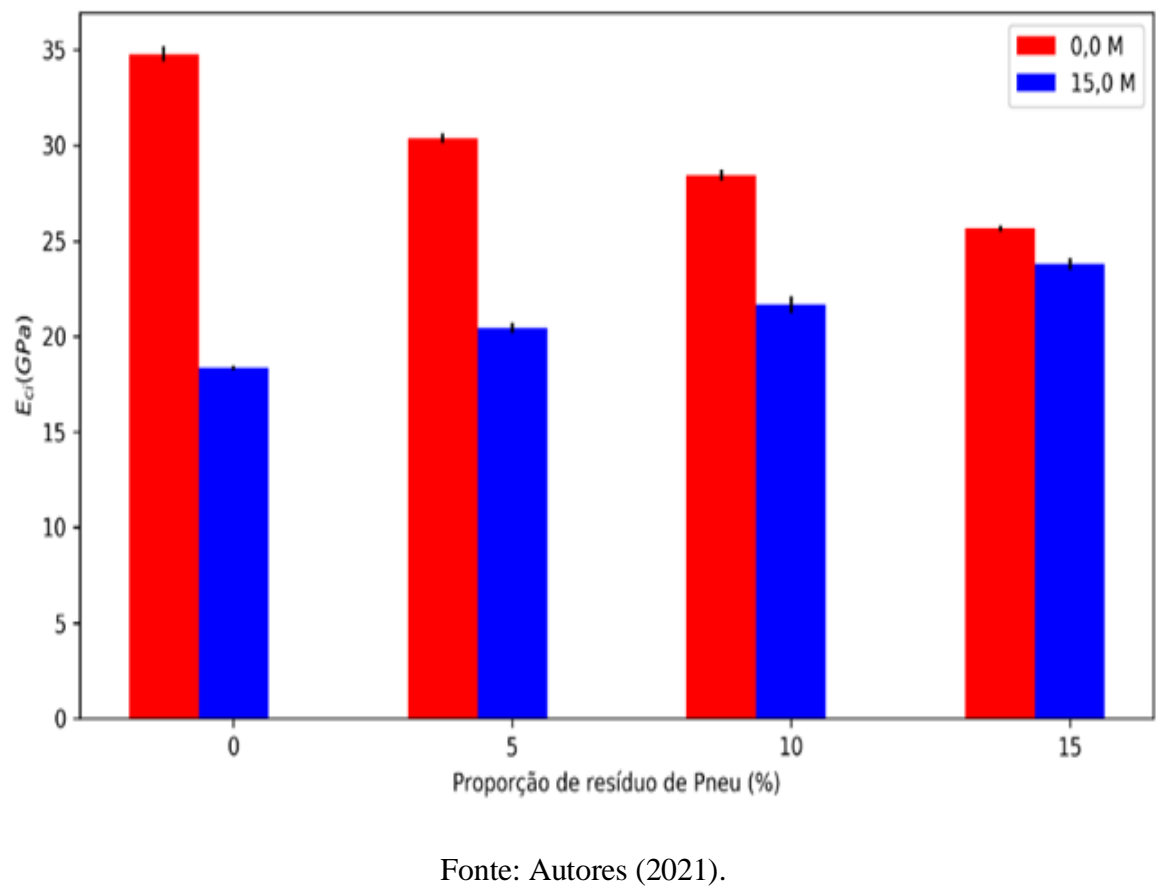

Entretanto, o valor do módulo de elasticidade aumentou de $(18,35 \pm 0,10)$ GPa da amostra REF-15M para $(23,79 \pm 0,30)$ GPa da amostra com 15 RP-15M. Deve-se verificar que a adição de Metacaulim, neste caso, aumentou o módulo de elasticidade do concreto, tornando esse concreto um pouco mais rígido e menos deformável aos 28 dias de idade.

A Figura 5 mostra os valores para a absorção de água por imersão individual do concreto aos 28 dias para o concreto endurecido. A absorção de água por imersão de cada amostra aumentou de $(5,06 \pm 0,38) \%$ da amostra REF. para $(7,35 \pm 0,40) \%$ da amostra com 15RP.

Este fato ocorre devido que as partículas da borracha funcionam como vazios no interior do concreto (Granzotto, 2013). Concretos de boa qualidade apresentam absorção de água inferior a 10\%, os traços com substituição 5RP a $15 \mathrm{RP}$ apresentaram absorção inferior a 10\% podendo ser, portanto, considerados de boa qualidade quanto à absorção (Gomes, 2018).

O comportamento da absorção de água e da resistência a compressão dos blocos de concreto na proporção de 15\%, $25 \%$ e $35 \%$ de resíduo de pneu foi investigado por Selung et al. (2013). Seus resultados mostraram que a absorção de água aumentou e a resistência a compressão diminuiu com o acréscimo da quantidade de resíduo de pneu no traço de concreto com substituição parcial de brita por resíduos de pneu nas proporções de 15\%, 25\% e 35\%.

Também observou que os valores de absorção de água diminuíram de $(12,78 \pm 0,22)$ MPa da amostra REF-15M para $(9,30 \pm 0,24) \mathrm{MPa}$ da amostra com 15\%RP-15M.

Além disso, observou-se também um aumento da absorção de água nas amostras ausentes de metacaulim para as amostras com adição de $15 \mathrm{M}$ de metacaulim. 
Figura 5. Absorção de água por imersão do concreto a 28 dias.

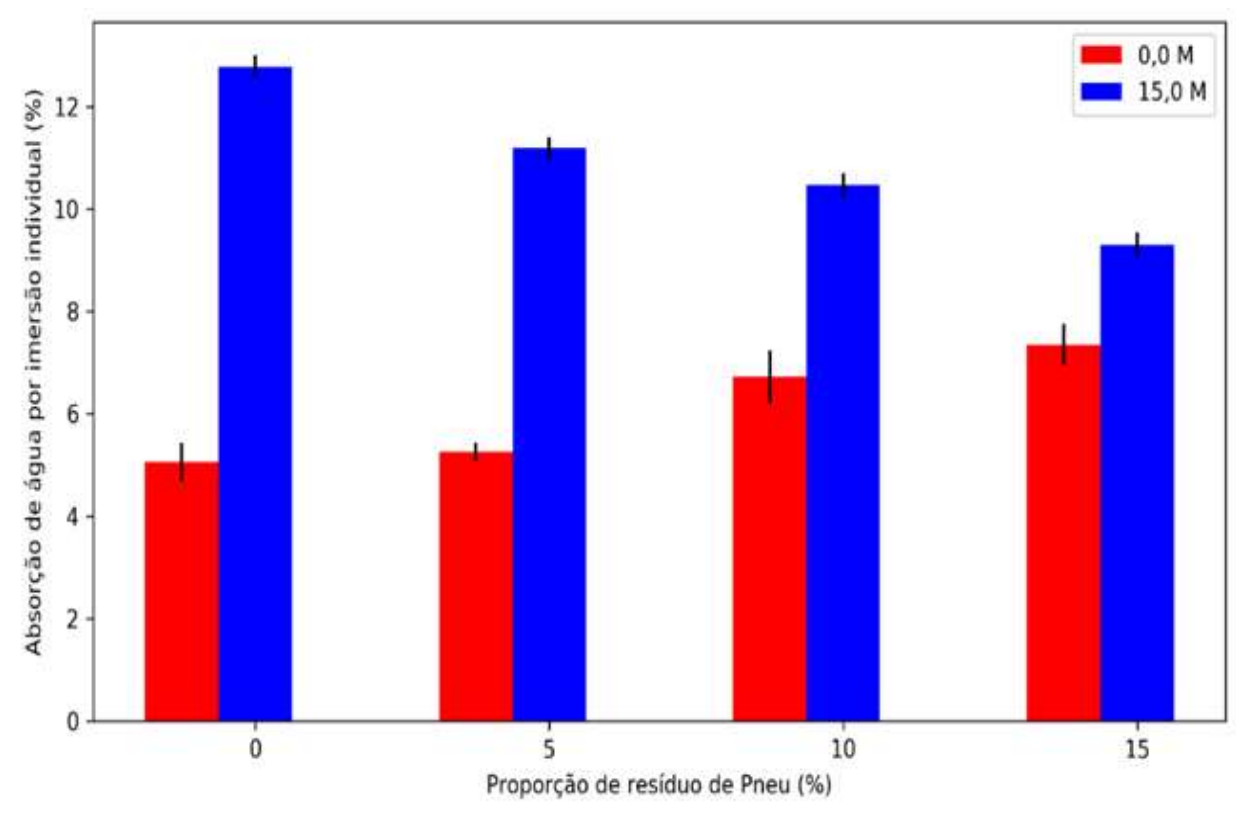

Fonte: Autores (2021).

Esse fato ocorre devido que o metacaulim promove um refinamento dos poros do concreto aumentando a absorção capilar (Resende et al., 2012).

Além disso, de acordo com Epps (1994), quando resíduos de pneu é adicionado à mistura de concreto, eles atraem o ar e repelem a água provocando o aumento no índice de vazios no concreto e consequentemente a absorção também aumenta.

A Figura 6 mostra os valores calculados para o índice de vazios das amostras aos 28 dias para o concreto endurecido. Os valores do índice de vazios aumentaram de $(12,07 \pm 0,77) \%$ da amostra REF para $(15,61 \pm 0,80) \%$ da amostra com $15 \mathrm{RP}$, pois os resíduos de pneu funcionam como vazios no interior da massa de concreto.

O aumento dos valores do índice de vazios também pode estar relacionado a outro fator, como o aumento do teor de ar aprisionado pois, quanto maior o teor de ar aprisionado maior a porosidade e menor a sua resistência (Freitas et al., 2009).

O valor do índice de vazios também diminuiu de $(22,45 \pm 0,36) \%$ da amostra REF-15M para $(19,61 \pm 0,38) \%$ da amostra com 15RP-15M. Este fato ocorre devido a reação pozolânica, que ocorrem nos poros do concreto, que são preenchidos por cristais de Silicato de cálcio hidratado (C-S-H) tornando o concreto menos poroso (Mota et al., 2016).

Além disso, observou-se também um aumento do índice de vazios nas amostras ausentes de metacaulim para as amostras com adição de $15 \mathrm{M}$ de metacaulim. 
Figura 6. Índice de vazios do concreto a 28 dias.

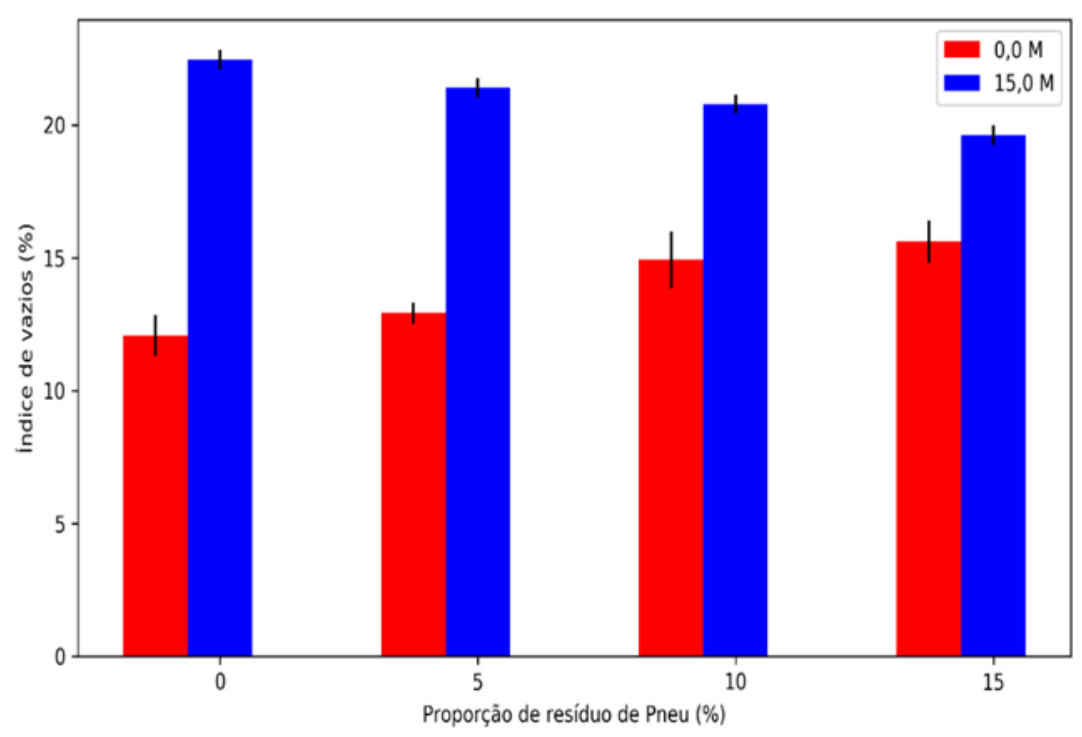

Fonte: Autores (2021).

A Figura 7 mostram a relação da absorção de água com o índice de vazios no concreto referencial ao $15 \mathrm{RP}$. Na Figura 7 observa-se que à medida que cresce os valores do índice de vazios, os valores da absorção de água também aumentam. A absorção de água aumenta com a utilização das partículas e fibras de borracha no concreto. O aumento da absorção está diretamente relacionado com a porcentagem de Resíduo, à medida que aumenta a porcentagem de substituição do agregado miúdo, ocorre um aumento na absorção de água (Gomes, 2018).

Segundo a (NBR 9781, 2013), a absorção de água, expressa em porcentagem, representa a porosidade do concreto, devido à penetração de água em seus poros permeáveis, em relação à sua massa em estado seco.

Figura 7. Relação da absorção de água com índice de vazios com resíduo de pneu.

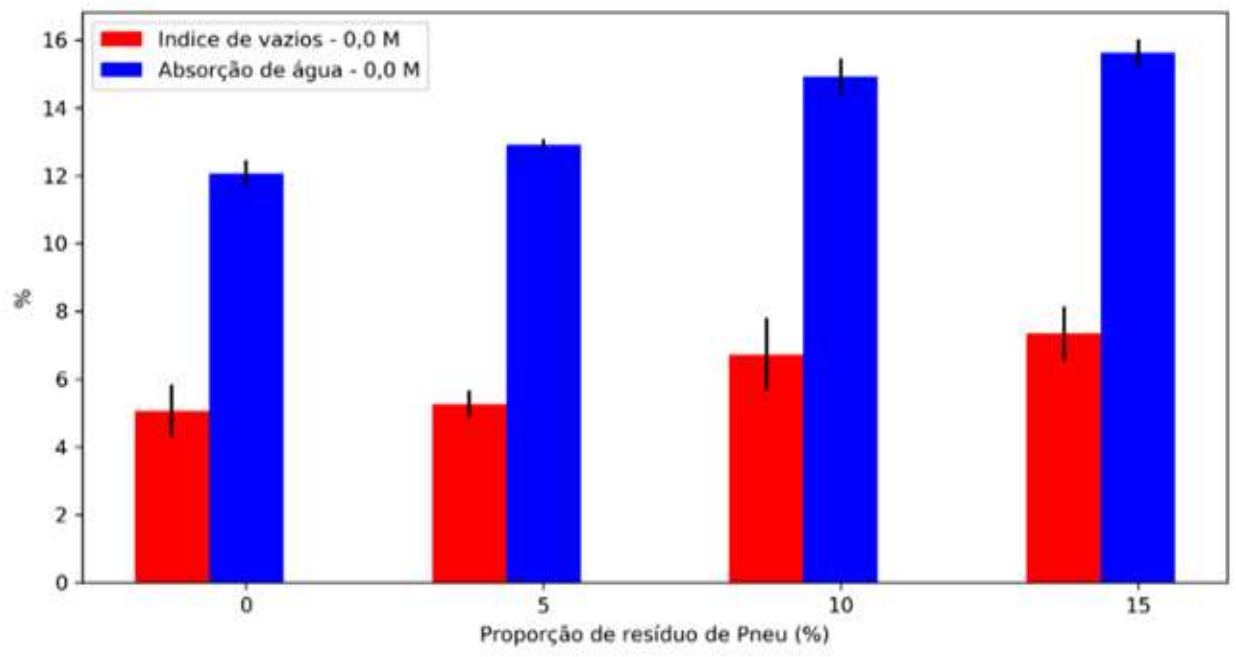

Fonte: Autores (2021).

A Figura 8 mostra a relação da absorção de água com o índice de vazios no concreto referencial ao 15RP com 15\% de metacaulim. A Figura 8 mostra que os valores da absorção de água diminuíram com o decréscimo do índice de vazios. 
Com relação à absorção de água por imersão, os resultados indicam que a adição de $15 \%$ de metacaulim em substituição ao cimento Portland reduz significativamente a absorção de água no concreto e consequentemente o índice de vazios.

Figura 8. Relação da absorção de água com índice de vazios com resíduo de pneu e metacaulim.

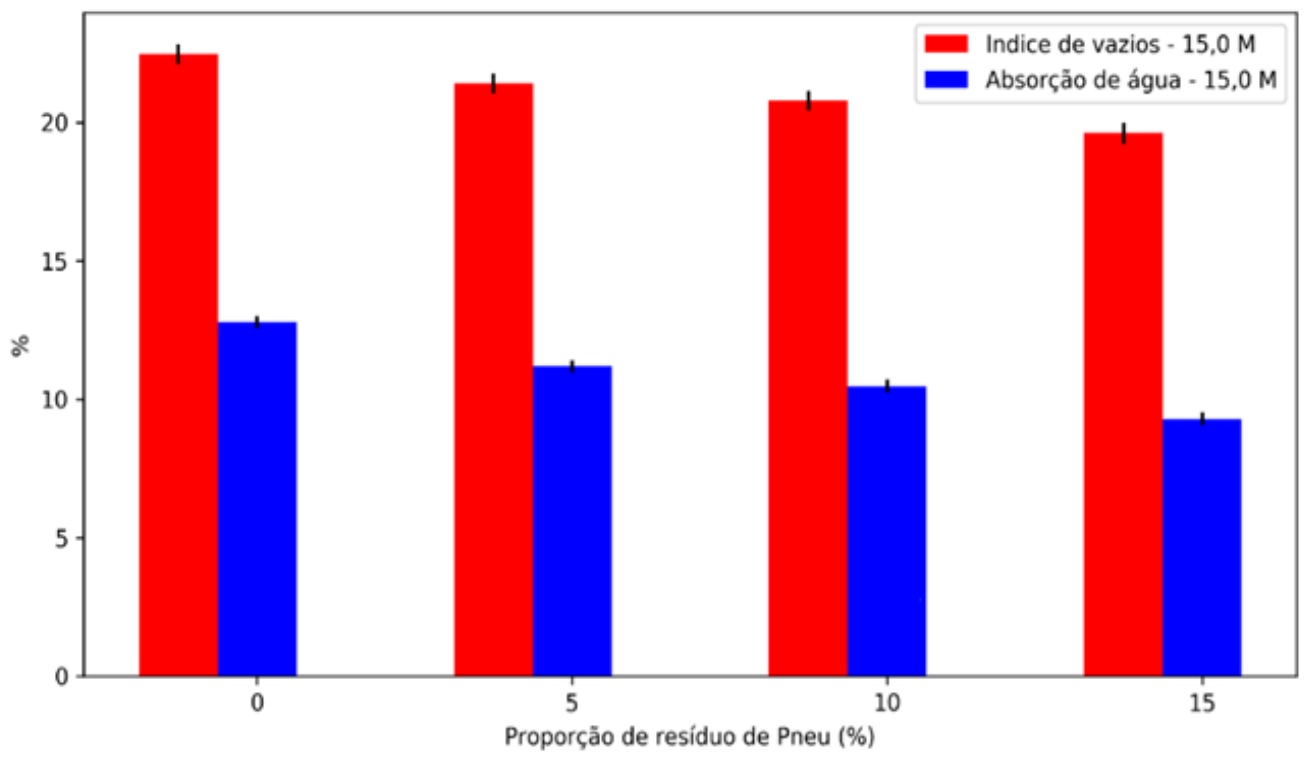

Fonte: Autores (2021).

\section{Conclusão}

Através dos resultados apresentados observa-se que não houve alteração nos valores da trabalhabilidade do concreto REF para o concreto com 5RP. Entretanto, observa-se um aumento trabalhabilidade do concreto com 10RP. Com a substituição de cimento por 15\% de metacaulim, não houve alteração nos valores da trabalhabilidade do concreto REF-15M para o concreto com 5RP-15M. Entretanto, da amostra 10RP-15M para o concreto com 15RP-15M observa-se um aumento na trabalhabilidade. Através dos resultados obtidos, identifica-se que a adição de resíduo de pneu diminui a resistência a compressão e com a substituição de cimento de 15\% de metacaulim, a resistência à compressão aumenta.

Através dos resultados obtidos, identifica-se que a adição de resíduo de pneu diminui o módulo de elasticidade. Entretanto, observou-se também que com a substituição de $15 \%$ de metacaulim por cimento, o módulo de elasticidade aumenta. Através dos resultados obtidos, identifica-se que a adição de resíduo de pneu aumenta a absorção de água. Entretanto, observou-se também que com a substituição de $15 \%$ de metacaulim por cimento, a absorção de água diminui.

Do ponto de vista tecnológico, em relação ao concreto com substituição de areia pela borracha, verificou-se que teores de substituição reduz a resistência à compressão.

Pela análise geral dos resultados obtidos no trabalho mostra que a inserção do metacaulim com o resíduo de borracha de pneu em misturas de concreto pode proporcionar diversas vantagens técnicas em relação aos concretos convencionais como, por exemplo o aumento da resistência a compressão e módulo de elasticidade, diminuição da porosidade, tornando o concreto menos permeável. Assim, com essas vantagens técnicas, o concreto pode ser aplicado em piso de ciclovias, blocos para meios fios e calçadas para pedestres. Para sugestões de trabalhos futuros sugere-se investigar a microestrutura e relacioná-las com as propriedades físicas e mecânicas do concreto convencional. Também desenvolver estudo, utilizando os mesmos teores de metacaulim, com monitoramento do concreto para várias idades, correlacionando a carbonatação com outros parâmetros de durabilidade assim como a resistividade elétrica do concreto, permeabilidade ao ar e à água, difusão de cloretos, contemplando 
as mudanças microestruturais.

\section{Referências}

American Society For Testing And Materials. ASTM C792. (2020). Standard Test Method for Effects of Heat Aging on Weight Loss, Cracking, and Chalking of Elastomeric Sealants.

Associação Brasileira De Normas Técnicas. ABNT NBR 16605. (2017). Cimento portland e outros materiais em pó - Determinação da massa específica. Rio de Janeiro.

Associação Brasileira De Normas Técnicas. ABNT NBR 5738:2015 Versão Corrigida:2016. (2015). Concreto - Procedimento para moldagem e cura de corpos-de-prova.

Associação Brasileira De Normas Técnicas. ABNT NBR 5739. (2018). Concreto - Ensaio de compressao de corpos-de-prova cilindricos.

Associação Brasileira De Normas Técnicas. ABNT NBR 7212. (2012). Execução de concreto dosado em central.

Associação Brasileira De Normas Técnicas. ABNT NBR 8522. (2017). Concreto - Determinação do módulo estático de elasticidade à compressão.

Associação Brasileira De Normas Técnicas. ABNT NBR 9781. (2013). Peças de concreto para pavimentação - Especificação e métodos de ensaio.

Associação Brasileira De Normas Técnicas. NBR 6118. (2014). Projeto de estruturas de concreto - Procedimento.

Associação Brasileira De Normas Técnicas. NBR 9778. (2009). Argamassa e concreto endurecidos - Determinação da absorção de água, índice de vazios e massa específica.

Associação Brasileira De Normas Técnicas. NBR NM 248. (2003). Agregados - Determinação da composição granulométrica.

Associação Brasileira De Normas Técnicas. NBR NM 52. (2009). Agregado miudo - Determinacao de massa especifica e massa especifica aparente.

Associação Brasileira De Normas Técnicas. NBR NM 53. (2009). Agregado graúdo - Determinação de massa específica, massa específica aparente e absorção de água.

Associação Brasileira De Normas Técnicas. NBR NM 67. (1998). Ensaio de Abatimento do Concreto (Slump Teste).

Barbuta, M., Diaconu, D., Erbanoiu, A. A., Timu, A. B., \& Gradinaru, C. M. (2017). Effects of Tire Wastes on the Mechanical Properties of Concrete. Procedia Engineering, 181, 346-350.

Bensoh, C. (1995). "Using shredded scrap tires in civil and environmental construction". Resource Recycling, 95, 1-4.

Congkou, S., Sunpoon, C., \& Agrela, F. (2011). Comparisons of natural and recycled aggregate concretes prepared with the addition of different mineral admixtures. Cement and Concrete Composites, 33, 788-795.

Epps, J. A. (1994). Uses of Recycled Rubber Tires in Highways. Synthesis of Highway Practice(198).

Estrela, C. (2018). Metodologia Científica: Ciência, Ensino, Pesquisa. Editora Artes Médicas.

Fioritti, C. F., Ino, A., \& Akasaki, J. L. (2007). Avaliação de blocos de concreto para pavimentação intertravada com adição de resíduos de borracha provenientes da recauchutagem de pneus. Ambiente Construído, 7, 43-54.

Freitas, C., Carlos, J., Franke, K., Joukoski, A., \& Filho, C. V. (2009). Desempenho físico-químico e mecânico de concreto de cimento Portland com borracha de estireno-butadieno reciclada de pneus. Quím. Nova, 32, 913-918.

Gomes, L. G. (2018). Utilização de resíduos de recapagem de de pneus para produção de concreto leve estrutural. Grupo de Mineralogia e Geoquímica Aplicada, 5, 1-18.

Granzotto, L. e. (2013). Mechanical Properties of Structural Concrete with Partial Replacement of Fine Aggregate by Tire Rubber. Acta Scientiarum, 35, 3944.

Modoi, O. C.; Sabru, C. (2017). The recycling of the rubber waste by incorporation into the cement matrices. Studia Ubb Ambientum, 12, 63-74.

Moreira, J. F., Fidelis, V. R., \& Dias, J. F. (2014). Concreto com borracha de pneus aplicado em ciclovia. Holos Environment, 14, 185-197.

Mota, J. M., Oliveira, R. A., \& Carneiro, A. M. (2016). Durabilidade de argamassas com adição de metacaulim para reforço de alvenaria. Revista Matéria., 21, $1105-1116$.

Nacif, G. L., Panzera, T. H., \& Strecker, K. (2012). Investigations on cementitious composites based on rubber particle waste additions. Materials Research, $16,259-268$.

Rameswari, S. e. (2017). Experimental Study on the Mechanical behaviour of Crumb rubber in High Strength Concrete. International Research Journal of Engineering and Technology, 4, 2270-2273.

Resende, M. L., Nascimento, J. W., Neves, G. A., Silva, F. L., Leal, A. F., \& Ferreira, H. C. (2012). Uso de metacaulim em concreto seco: uma abordagem por superfície de resposta. Ambiente Construído, 12, 135-146. 
Research, Society and Development, v. 10, n. 5, e2410514463, 2021

(CC BY 4.0) | ISSN 2525-3409 | DOI: http://dx.doi.org/10.33448/rsd-v10i5.14463

Romualdo, A. C., dos Santos, D. E., Castro, L. M., Menezes, W. P., Pasqualetto, A., \& dos Santos, O. R. (2011). Pneus Inservíveis como Agregados na Composição de Concreto para Calçadas de Borracha. 3rd International Workshop Advances in Cleaner Production.

Rossignolo, J. A. e Oliveira, I. 1. (2007). Efeito do Metacaulim nas propriedades do concreto leve estrutural. Acta Sci. Technol, 29, 55-60.

Selung, C. S., Menegotto, M. L., Menegotto, A. G., \& Pavan, R. C. (2013). Avaliação de blocos de concreto para alvenaria com adição de resíduos de borracha. Holos Enviroment, 13, 212-223.

Silva, L. R., Silva, J. A., Francisco, M. B., Ribeiro, V. A., Souza, M. H., Capelatto, P., \& Mello, M. L. (2020). Polymeric Waste from Recycling Refrigerators as an Aggregate for Self-Compacting Concrete. Sustainability, 20, 8731.

Silva, L. S., Nogueira, M. H., Lima, G. K., Cipriano, F. S., \& Batista, N. J. (2019). Concreto alternativo com utilização de resíduos de borracha de recauchutagem de pneus para elementos e componentes pré-fabricados. Revista de Ciência e Tecnologia, 5, 1-19.

Singh A. K. e Patel, D. (2017). Strength and Durability Test of Rubberized Concrete with Metakaolin. Imperial Journal of Interdisciplinary Research, 03, 285287.

Souza, M. M., Camara, T. A., \& Akasaki, J. L. (2016). Estudo do Teor de Metacaulim em Concretos de Alto Desempenho. ANAP Brasil, 9, 47-58.

Wanke, C. H., Barbosa, L. G., Hubner, J. V., \& Horovit, F. (2012). Recuperação Hidrofóbica de Polipropileno Tratado por VUV ou Plasma. Polímeros, 22, 158-163. 